\title{
Occupational Tasks Influencing Lung Function Status and Respiratory Health Problems among Brass Utensils Factory Worker
}

\author{
Author \\ Dr Nusaer Chowdhury \\ DPM (Injury, Snake bite, GBV), NCDC, Dhaka, Bangladesh
}

\begin{abstract}
The brass metal workers are affected by the flakes of brass during making of brass made utensils that causes the decrement as well as impairments of pulmonary functions. The aim of the present study is to evaluate the pulmonary function status and respiratory health problems of the workers engaged in manufacturing of brass made utensils and polishing. A standard questionnaire was followed to note the symptoms, like cough, breathlessness and chest tightness, etc. The study was carried out at Dhamrai upazilla in the district of Dhaka, Bangladesh. The pulmonary function status assessment was done by spirometric method using electronic hand held spirometer by CONTEC SO10. Among total 113 respondents, 9.7\% were suffering from cough with phlegm for 3 months or more, about $96 \%$ were suffering from wheezing with shortness of breath, about 39.9\% were suffering from breathlessness during walking fast. Respiratory problems by family history was found statistically not significant. Respiratory health problem by FVC and FVAl values in respondents of different age group, different duration of work, smoking habit was found to be statistically not significant. The respiratory function impairments among the brass made utensil workers might be due to their exposure in to the work environment. Proper training and education should be provided to workers about the health hazards associated with exposure to irritant gas and the proper use of respiratory protection.
\end{abstract}

Keywords: Lung Function Status, Respiratory Health Problems, Brass Utensils.

\section{Introduction}

A healthy workforce is vital for sustainable social and economic development on a local, national, as well as at global level. The classical approach to ensuring health and safety in the workplace depends mainly on the enactment of legislation and inspection of workplaces to ensure effect on living conditions. This approach has been effective in controlling many specific occupational hazards since the Industrial revolution; still it has not been very effective in developing countries ${ }^{1}$. The industrial revolution and the great economic success that accompanied had a wide variety of victims. Ancient metalworkers in the area now known as Syria or eastern Turkey knew how to melt copper with tin to make a metal called bronze as early as 3000 B.C. Sometimes they also made brass without knowing it, because tin and zinc ore deposits are sometimes found together, and the two materials have similar colors and properties. The first metal cartridge casings for firearms were introduced in 1852. Although several different metals were tried, brass was the most successful because of its ability to expand and seal the breech under pressure when the cartridge was first fired, then contract immediately to allow the empty cartridge casing to be extracted from the firearm. This property led to the development of rapid-fire automatic weapons. The industrial revolution and the great economic success that accompanied had a wide variety of 
victims. Factory work is very different from other types of labor ${ }^{2}$. In Dhamrai about 100 brass manufacturing units of different scale are being run with a small team of 5 to 15 workers under one roof and in that way; those units employ more than 5000 people directly or indirectly. Occupational health hazards $(\mathrm{OHH})$ refer to the potential risks to health and safety for those who work outside the home. According to the $\mathrm{WHO}$, this $\mathrm{OHH}$ represents about 70 percent of adult men and up to 60 percent of adult women throughout the world. Health Hazards related to Occupation can be classified into Physical, Chemical, biological and Ergonomics hazards ${ }^{3}$. Workers who directly work in Brass industry faces many of above stated health hazards. During working in different section like foundry, production and sharpening, quality control etc. of the brass industry; they come across various hazards like Air pollution (through brass fume inhalation), sound pollution (like noise of machines) and other skin irritants by direct contact with heavy metals or chemicals and so on. As various brass industry owners do not follow labor rules, workers' working hours are 10 - 12 hours daily ${ }^{4}$.

Due to that, many times they compelled to suppress natural physiological urges (due to work engagement), as well as to continue work in some specific posture for long time period. This entire situation also leads to one or more physical or mental health problems (even other than industrial hazards) to ${ }^{1}$. The causes of occupational diseases are often overlooked by health care providers as occupational diseases remains identical in clinical and pathological presentation to non-occupational diseases ${ }^{5}$.

\section{Materials and Methods \\ Study Type}

This was a cross sectional study aiming to assess the lung function status and respiratory problems among the Brass utensil factory workers.

\section{Study Population}

The study population was workers of different brass industries of Dhamrai upazilla, Dhaka.

\section{Study Place}

The was obtained from 10 industries of two villages, kaissa para and hindu para in Dhamrai upazilla, Dhaka district. Majority of the industries were situated in these areas.

\section{Study Period}

Total study period was one year from 1st January 2017 to 31st December 2017.

\section{Sampling Method}

In this study convenient sampling was done on the basis of some inclusion, exclusion criteria.

\section{Inclusion Criteria}

1. Workers who are willing to participate in the study.

2. Workers in employment for more than one year.

\section{Exclusion Criteria}

1. Workers with known respiratory deformities.

2. Workers with known chronic conditions like childhood asthma, malignancy, Respiratory TB.

\section{Sample Size}

At $95 \%$ confidence interval and within $10 \%$ margin of error, sample size of this study was 124 .

\section{Research Instrument \\ Questionnaire}

Semi structured questionnaire with both close and open ended question was used in the study. It was designed on the basis of recommended respiratory disease questionnaire for use with adult and children in epidemiological research which was a part of American Thoracic Society division of lung disease. Adult questionnaire part was used in this study.

\section{Check list}

The checklist was designed to record findings of

1. Height

2. Weight

3. FEV1

4. FVC

5. FEV1/FVC

6. PEFR

\section{Data Collection Tools}

1. Paper

2. Pen 
3. Height scale

4. Weight scale

\section{Spirometer}

\section{Data Collection Technique}

On the schedule date, data was collected from the selected factories by face to face interview method and on the basis of selection criteria. At first written informed consent had been taken from the respondents after explaining the purpose of the study.

For recording lung function electronic hand held spirometer by CONTEC SO10 Spirometer was used which had a display and also had capabilities of recording data in case of repeated measurement. The procedure was explained and demonstrated first then the values of FEV1, FVC, FEV1/FVC, PEFR were recorded after 3 repeated procedures for each of the respondents. The height of the respondents was measured and then the observed pulmonary function values and height were noted in the check list.

\section{Results}

Among total 113 respondents, respondents 9.7\% were suffering from cough with phlegm for 3 months or more \& rest of the respondents $90.3 \%$ were not suffering from cough with phlegm. About 96\% were suffering from wheezing with shortness of breath, and $85 \%$ were not suffering from wheezing with shortness of breath. About 39.9\% were suffering from breathlessness during walking fast and $61.1 \%$ were not suffering from breathlessness. Among total 113 respondents, family history having respiratory health problem had $32.7 \%$ \& rest of the respondents $67.3 \%$ had no family history. $77 \%$ had been suffering respiratory health problems. And rest of the participants $23 \%$ were healthy.

Among the 113 respondents FVC of the respondents in different age category ranged from 1.24-3.32 $\mathrm{L} / \mathrm{sec}$ and their mean FVC was $1.99( \pm 0.438) \mathrm{L} / \mathrm{sec}$. The FVC of respondents of different age group was found to be statistically not significant $(\mathrm{P}=0.170)$. Respondents who were in 18-30 age group had higher mean FVC $2.19( \pm 0.342) \mathrm{L} / \mathrm{sec}$ respectively than respondents from other age group. Respondents who were in 31-45 age group had the lowest mean FVC 1.949( \pm 0.477$)$ L/sec respectively than respondents from other age group.

Among the 113 respondents FVC of the respondents in different smoking habit ranged from 1.24-3.32 $\mathrm{L} / \mathrm{sec}$ and their mean FVC was $1.99( \pm 0.438) \mathrm{L} / \mathrm{sec}$. The FVC of respondents of different smoking habit was found to be statistically not significant $(\mathrm{P}=0.452)$. Respondents who were smoker had higher Mean FVC 2.01 $( \pm 0.441) \mathrm{L} / \mathrm{sec}$ respectively than respondents from other duration of work group. According to GOLDs criteria Respiratory Problem was considered when the percent predict FVC value was below $80 \%$. Table shows FVC values according to cutting section. Here $99 \%$ respondents from cutting and wielding section had reduced FVC values and $1 \%$ had normal FVC values. And among the respondents from polishing section $100 \%$ had reduced FVC and $00 \%$ had normal FVC. And among the respondents from cleaner and helper section $100 \%$ had reduced FVC and $00 \%$ had normal FVC. Respiratory health problem by FVC values in respondents was found to be statistically not significant.

Among the 113 respondents FEV1 of the respondents in different age category ranged from 0.76-3.15 L/sec and their mean FEV1 was $1.75( \pm 0.456) \mathrm{L} / \mathrm{sec}$. The FEV1 of respondents of different age group was found to be statistically not significant $(\mathrm{P}=0.220)$. Respondents who were in 1830 age group had higher mean FEV1 1.94( \pm 0.389$)$ $\mathrm{L} / \mathrm{sec}$ respectively than respondents from other age group.

Among the 113 respondents FEV1 of the respondents in different duration of work ranged from $0.70-3.15 \mathrm{~L} / \mathrm{sec}$ and their mean FEV1 was $1.62( \pm 0.493) \mathrm{L} / \mathrm{sec}$. The FEV1 of respondents of different duration of work was found to be statistically not significant $(\mathrm{P}=0.465)$. Respondents who were in duration of work 22-30 years' group had higher Mean FEV1 1.70 $( \pm 0.476)$ L/sec respectively than respondents from other duration of work group. 
Among the 113 respondents FEV1 of the respondents in different smoking habit ranged from 0.76-3.15 L/sec and their mean FEV1 was $1.75( \pm 0.456) \mathrm{L} / \mathrm{sec}$. The FEV1 of respondents of different smoking habit was found to be statistically not significant $(\mathrm{P}=0.961)$. Respondents who were smoker had higher Mean FVC 1.76( \pm 0.434$) \mathrm{L} / \mathrm{sec}$ respectively than respondents from other smoking group.

According to GOLDs criteria Respiratory Problem was considered when the percent predict FEV1 value was below $80 \%$.

FEV1 values according to cutting section shows that about $99 \%$ respondents from cutting and wielding section had reduced FEV1 values and 1\% had normal FEV1 values. And among the respondents from polishing section $100 \%$ had reduced FEV1 and $00 \%$ had normal FEV1. And among the respondents from cleaner and helper section $100 \%$ had reduced FEV1 and 00\% had normal FEV1. Respiratory health problem by FEV1 values in respondents was found to be statistically not significant.

According to GOLDs criteria Respiratory Problem was considered when the percent predict FVC value was below $80 \%$. Table shows FVC values according to respiratory problems. Here $99 \%$ respondents with respiratory problems had reduced $\mathrm{FVC}$ values and $1 \%$ had normal FVC values. And among the respondents without any respiratory problems $100 \%$ had reduced FVC and $00 \%$ had normal FVC. Respiratory health problem by FVC values in respondents was found to be statistically not significant.

According to GOLDs criteria Respiratory Problem was considered when the percent predict FEV1/FVC value was below 0.7. Table shows FEV1/FVC values according to respiratory problems. Here $4.60 \%$ respondents with respiratory problems had reduced FEV1/FVC values and $95.40 \%$ had normal FEV1/FVC values. And among the respondents without any respiratory problems $3.86 \%$ had reduced FEV1/FVC and $96.14 \%$ had normal FEV1/FVC. Respiratory health problem by FEV1/FVC values in respondents was found to be statistically not significant.
Table-1: Distribution of respiratory health problems by age of the respondents $(n=113)$

\begin{tabular}{|l|c|c|c|}
\hline \multirow{2}{*}{ Age Cat. (year) } & \multicolumn{2}{|c|}{ Respiratory Health Problems } & \multirow{2}{*}{ Total } \\
\cline { 2 - 3 } & Yes & No & \\
\hline $18-30$ & $12(80)$ & $3(20)$ & 15 \\
\hline $31-45$ & $27(77.14)$ & $8(22.86)$ & 35 \\
\hline $46-64$ & $48(76.19)$ & $15(23.81)$ & 63 \\
\hline Total & $87(77)$ & $26(23)$ & 113 \\
\hline
\end{tabular}

Table-2: Distribution of respiratory health problems by level of education of the respondents $(n=113)$

\begin{tabular}{|l|c|c|c|}
\hline \multirow{2}{*}{ Level of Education } & \multicolumn{2}{|c|}{ Respiratory Health Problems } & \multirow{2}{*}{ Total } \\
\cline { 2 - 3 } & Yes & No & \\
\hline Illiterate & $31(75.6)$ & $10(24.4)$ & 41 \\
\hline Primary & $52(80)$ & $13(20)$ & 65 \\
\hline Secondary \& above & $4(57.1)$ & $3(42.9)$ & 7 \\
\hline Total & $87(77)$ & $26(23)$ & 113 \\
\hline
\end{tabular}

Table-3: Distribution of respiratory health problems by working section of the respondents $(n=113)$

\begin{tabular}{|l|c|c|c|}
\hline \multirow{2}{*}{ Working section } & \multicolumn{2}{|c|}{ Respiratory Health Problems } & \multirow{2}{*}{ Total } \\
\cline { 2 - 3 } & Yes & No & \\
\hline Cutting \& wielding & $60(75)$ & $20(25)$ & 80 \\
\hline Polishing & $13(86.7)$ & $2(13.3)$ & 15 \\
\hline Cleaner \& helper & $14(77.8)$ & $4(22.2)$ & 18 \\
\hline Total & $87(77)$ & $26(23)$ & 113 \\
\hline
\end{tabular}

Table-4: Comparison of FVC of respondents by smoking habit $(\mathrm{n}=113)$

\begin{tabular}{|l|c|c|c|c|}
\hline \multirow{2}{*}{ Smoking habit } & \multicolumn{4}{|c|}{ FVC of respondents } \\
\cline { 2 - 5 } & $\mathrm{N}$ & Mean \pm SD & Min & Max \\
\hline Yes & 77 & $2.01 \pm 0.441$ & 1.30 & 3.22 \\
\hline No & 36 & $1.95 \pm 0.436$ & 1.24 & 3.32 \\
\hline Total & 113 & $1.99 \pm 0.438$ & 1.24 & 3.32 \\
\hline
\end{tabular}

Table-5: Distribution of respiratory health problems by smoking habit of the respondents $(n=113)$

\begin{tabular}{|l|l|l|l|}
\hline \multirow{2}{*}{ Smoking Habit } & \multicolumn{2}{|l|}{ Respiratory Health Problems } & \multirow{2}{*}{ Total } \\
\cline { 2 - 3 } & Yes & No & \\
\hline Smoker & $58(80.6)$ & $14(19.4)$ & 72 \\
\hline Non smoker & $29(70.7)$ & $12(29.3)$ & 41 \\
\hline Total & $87(77)$ & $26(23)$ & 113 \\
\hline
\end{tabular}

Table-6: Comparison of FVC of respondents by working section $(n=113)$

\begin{tabular}{|l|c|c|}
\hline \multirow{2}{*}{ Working section } & \multicolumn{2}{|c|}{ FVC of respondents } \\
\cline { 2 - 3 } & Reduced $(<80 \%)$ & Normal $(>80 \%)$ \\
\hline Cutting \& wielding & $79(99)$ & $1(1.00)$ \\
\hline Polishing & $15(100)$ & $0(0.00)$ \\
\hline Cleaner \& helper & $18(100)$ & $0(0.00)$ \\
\hline Total & $112(99)$ & $1(1.00)$ \\
\hline
\end{tabular}

Table-7: Comparison of FEV1 of respondents by working section $(\mathrm{n}=113)$

\begin{tabular}{|l|c|c|}
\hline \multirow{2}{*}{ Working section } & \multicolumn{2}{|c|}{ FEV1 of respondents } \\
\cline { 2 - 3 } & Reduced $(<80 \%)$ & Normal $(>80 \%)$ \\
\hline Cutting \& wielding & $74(92.5)$ & $6(7.5)$ \\
\hline Polishing & $15(100)$ & $0(0.00)$ \\
\hline Cleaner \& helper & $17(94.4)$ & $1(5.6)$ \\
\hline Total & $113(99)$ & $1(1.00)$ \\
\hline
\end{tabular}




\section{Discussion}

Family history of having respiratory health problem shows $37(32.7 \%)$ were suffering from respiratory health problems among whom 29 had previous history of respiratory health problems and 8 had none. And 58 were suffering from respiratory health problems but had no family history of respiratory health problems and 26 had no respiratory health problems and no family history also. No significance was found among respiratory health problems and family history $(\mathrm{p}=0.807)$. Among the respondents of cutting and wielding section 60 $(75 \%)$ were suffering from respiratory health problems and 20(25\%) were not. Among polishers $13(86.7 \%)$ were suffering from respiratory health problems and $4(22.2 \%)$ were not, and among the cleaner and helpers $14(77.8 \%)$ were suffering from respiratory health problems and 26(23\%) were not. It shows that the highest numbers of respiratory health problem sufferer are from polisher section. Then cleaner and helpers and then cutting and wielding section workers.

The respiratory health problems percentage can be compared, where it was found that among the weilders $3.12 \%$ suffered from respiratory health problems and among the polishers $11.11 \%$ were suffering from respiratory health problems ${ }^{6}$. In this study it was found that $50(44.2 \%)$ were working for less than 20 years. And 32 (28.3\%) worked for 2230 years and $31(27.4 \%)$ were working for more than 35 years.

There mean working year were 0.832 and $\mathrm{SD}= \pm 0.883$. It was seen that workers with more working years' experience are less in number which may be due to decreasing usage of brass utensils with decreasing economical turnover which is leading them to change their occupation.

In this study it was found that among the workers who were working for less than 20 years 38(76\%) were suffering from respiratory health problems. And among the workers who were working for 2130 years $26(81.2 \%)$ were suffering from respiratory health problems. And among the workers who were working for more than 30 years $23(74.2 \%)$ were suffering from respiratory health problems. The result can be compared with a study where it was seen that in younger age prevalence of respiratory problems are higher, the cause of which may be due to initial high exposure to fumes and dusts ${ }^{7}$. Among the respondents it was found that $38.9 \%$ were suffering from breathlessness during walking fast which was compared with any other person who are not employed in brass production. This indicates there are long term respiratory and cardiac diseases. And $61.1 \%$ did not have any kind of problem with the same procedure.

In this study it was found that $77 \%$ respondents were suffering from respiratory problems and $23 \%$ were not. Here respiratory problem denotes as suffering from any one or all of the following conditions for 6 or more than 6 weeks which are cough, cough with phlegm, wheezing, breathlessness, chest tightness, COPD. The finding can be compared with a cross sectional study where among 50 brass workers $8 \%$ were suffering from obstructive type of impairment. Among them 3.12\% were utensil makers and $11.11 \%$ were polishers ${ }^{8}$.

Among the workers who were aged between 18-30 years 15 respondent, $80 \%$ of them were suffering from respiratory problems. And who were aged between 31-45 years 35 respondent, $77.14 \%$ were suffering from respiratory problems. And who were aged between 46-64 years the highest respondent 63 in number, $77 \%$ were suffering from respiratory problems. The age of respondent's potentiality was found statistically not significant in terms to respiratory problems. The result can be compared with a study where it was seen that in younger age prevalence of respiratory problems are higher, the cause of which may be due to initial high exposure to fumes and dusts and not using any $\mathrm{PPE}^{9}$.

Prevalence of respiratory problems among the 72 smokers were $80.6 \%$ and $19.4 \%$ did not have any respiratory problems. And among the 41 nonsmokers $70.7 \%$ were suffering from respiratory problems and $29.3 \%$ did not suffer. There was no significant relationship between smoking history and respiratory problems which is not significant. In this study it was seen that most of the smokers smoked more than 10 cigarettes and they started 
their first smoke when they start working on brass. The result can be compared, where prevalence of respiratory problems was higher for smokers. There was also higher prevalence of thoracic disorder among smokers of brass workers ${ }^{10}$.

Prevalence of workers who had family history of respiratory problems are 29 in number. Here 29 (78.4\%) had respiratory problems and $8(21.6 \%)$ did not. And among the 76 workers who had no family history 58(76.3\%) were suffering from respiratory problems and 26(23.7\%) were not suffering. Here respiratory problems by family history was found statistically not significant.

\section{Conclusion}

Among total respondents two third of respondents were suffering in respiratory health problems. Prevalence of respiratory health problems were higher in advanced age. Prevalence of respiratory health problems were increased with increasing years of exposure. Respiratory health problems were found to be significantly higher among respondents having smoking habit than in nonsmoking habit. Lung function status was found to be significant with different age group, sex, respiratory health problems. Two third of the workers had reduced lung function. There was no statistically significant difference found in potentiality of exposure and lung function abnormality. Poor lung function status was seen among the workers who worked in exposure section and long duration of working experience.

\section{References}

1. Pandya, D.H. and Ghumra, J., 2016. Recent and Futuristic Ayurveda Science.

2. World Health Organization, 2002. Occupational health: a manual for primary health care workers.Design by John Shimwell.

3. Jayawardana, P.L., De Alwis, W.R. and Fernando, M.A., 1997. Ventilatory function in brass workers of Gadaladeniya, Sri Lanka. Occupational medicine, 47(7), pp.411-416.
4. Logue, J.N., Koontz, M.D. and Hattwick, M.A., 1982. A historical prospective mortality study of workers in copper and zinc refineries. Journal of Occupational and Environmental Medicine, 24(5), pp.398hyhen.

5. Palmer, K.T., Cullinan, P., Rice, S., Brown, T. and Coggon, D., 2009. Mortality from infectious pneumonia in metal workers: a comparison with deaths from asthma in occupations exposed to respiratory sensitizers. Thorax

6. Ross, M.H. and Murray, J., 2004. Occupational respiratory disease in mining. Occupational medicine, 54(5), pp.304-310.

7. Kuo, H.W., Chang, C.L., Liang, W.M. and Chung, B.C., 1999. Respiratory abnormalities among male foundry workers in central Taiwan. Occupational medicine, 49(8), pp.499-505.

8. Kusaka, Y., Yokoyama, K., Sera, Y., Yamamoto, S., Sone, S., Kyono, H., Shirakawa, T. and Goto, S., 1986. Respiratory diseases in hard metal workers: an occupational hygiene study in a factory. Occupational and Environmental Medicine,43(7), pp.474-485.

9. Ostiguy, G., Vaillancourt, C. and Begin, R., 1995. Respiratory health of workers exposed to metal dusts and foundry fumes in a copper refinery. Occupational and environmental medicine,52(3), pp.204-210.

10. Rees, D. and Murray, J., 2007. Silica, silicosis and tuberculosis [State of the Art Series. Occupational lung disease in highand low-income countries, Edited by $\mathrm{M}$. Chan-Yeung. Number 4 in the series]. The International Journal of Tuberculosis and Lung Disease, 11(5), pp.474-484. 